\title{
ESTRATÉGIAS DE REPLICAÇÃO E SOLUÇÕES DE DESIGN PARA UMA ORGANIZAÇÃO CRIATIVA E COLABORATIVA: INOVAÇÃO SOCIAL NO ACESSO À LEITURA E EDUCAÇÃO BÁSICA
}

Replication Strategies and Design Solutions for a Creative and Collaborative Organization:

\section{BARAUNA, Debora}

Universidade Federal do Paraná - UFPR

debora.barauna1@gmail.com

TEIXEIRA, Edson Sidnei Maciel

Universidade Federal do Paraná - UFPR

edson.teixeira@ifsc.edu.br

CHAVES, Liliane Iten

Universidade Federal do Paraná - UFPR

lilianeitenchaves@idd.uff.br

\section{Resumo}

A inovação social têm emergido de organizações criativas e colaborativas. Pressupõe-se que tais iniciativas podem ser replicadas e/ou melhoradas por meio de soluções de design. Assim, o objetivo deste trabalho foi difundir a ideia da organização Omunga Grife Social. Esta iniciativa promove o acesso à leitura para crianças e adolescentes. O método aplicado foi o estudo de caso, apoiado pelo toolkit da Rede Internacional DESIS e ferramentas do design de serviços. Os resultados obtidos foram o delineamento do modelo de gestão da organização e o entendimento do seu sistema de atuação e processo de interação entre as partes interessadas.

Palavras-chave: Inovação social, Organizações criativas, Replicação, Soluções de Design

\section{Abstract}

Social innovation has emerged from creative and collaborative organizations. It is assumed that such initiatives can be replicated and/or improved through of design solutions. The objective of this study was to spread the idea of Omunga Social Grife organization. This initiative promotes access to reading for children and adolescents. The method used was the case study, supported by the toolkit DESIS International Network and service design tools. The obtained results were the delineation of organization's management model and the understanding of their actuation system and interaction process between the interested parts.

Keywords: Social innovation, Creative organizations, Replication, Design Solutions 


\section{INTRODUC̣ÃO}

A sociedade contemporânea em sua complexidade constitui-se como um imenso laboratório de ideias para a vida cotidiana, onde modos de ser e fazer se desdobram em novas soluções criativas. No design, em muitos casos, essas soluções expressam-se por atividades colaborativas (MANZINI, 2008).

A exemplo disto destaca-se a DESIS International Network (Design for Social Innovation and Sustainability), como uma rede internacional de laboratórios de design com base em universidades de diversos países orientada para a promoção e o apoio da mudança sustentável por meio da inovação social, da qualidade de vida cotidiana e do design para a sustentabilidade (DESISNETWORK, 2015).

No Brasil, a atuação da DESIS foi impulsionada pela realização do workshop "Design, inovação social e desenvolvimento sustentável", ministrado por Ezio Manzini em 2007 e 2008 e transmitido online para universidades de todo o país. Após essa experiência, a DESIS-Brasil (Design de Serviços e Inovação Social) foi formada com membros de algumas das principais universidades brasileiras. O propósito da Rede DESIS-Brasil é realçar os fatores que podem promover a inovação social para a sustentabilidade no país, por meio da elaboração de projetos ou pela difusão de casos promissores. Tanto no Brasil como no mundo, casos promissores de inovação social tem emergidos na forma de serviços de colaboração social, iniciativas de melhoria urbana, sistemas de produção distribuídos e desenvolvimento local sustentável (MANZINI et al., 2010).

Com esse cenário, uma iniciativa de inovação social brasileira foi estudada e apresentada nesse artigo como um exemplo de organização criativa e colaborativa. Assim, o objetivo desse trabalho foi difundir ideia da iniciativa em questão, por meio das estratégias de replicação e soluções de design indicadas por Manzini (2008). A estratégia de replicação é uma forma de agir para aumentar o impacto social e econômico das iniciativas de inovação social para multiplicá-las e conectá-las com a criação de amplas redes. Para isto, Manzini (2008, p.91) sugere o uso do toolkit "conjunto de instrumentos tangíveis e intangíveis concebidos e produzidos para simplificar uma tarefa específica". O autor aborda ainda a questão da integração do toolkit com as soluções habilitantes ou facilitadoras de design, que se definem como "um sistema de produtos, serviços, comunicação e o que mais for necessário para implementar a acessibilidade, a eficácia e a replicabilidade de uma organização colaborativa" (MANZINI, 2008, p.84).

Por fim, no encadeamento desse artigo são apresentados os conceitos de inovação social, o papel do design na difusão de ideias, as estratégias e os métodos empregados no trabalho, bem como os resultados e a discussão

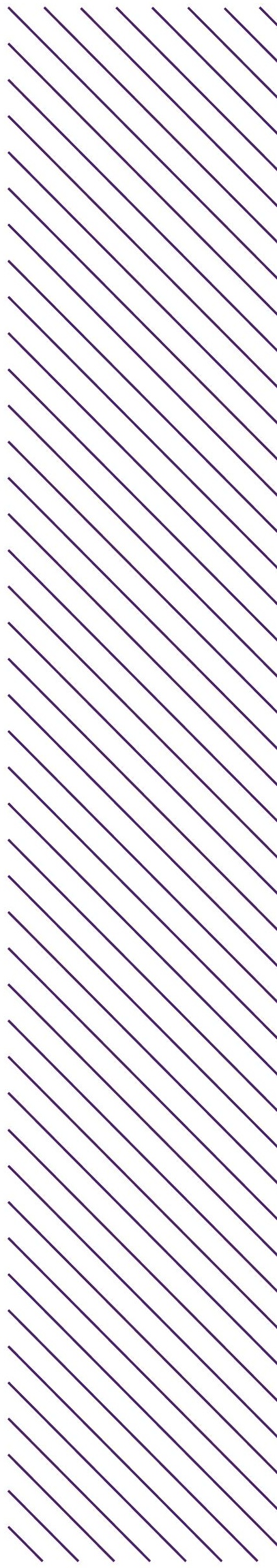


obtidos com o estudo de caso realizado.

\section{INOVAC̣ÃO SOCIAL}

Segundo Manzini (2008) a inovação social abrange um campo amplo de possibilidades na medida que envolve a criação de novas soluções (estratégias, conceitos e métodos) para o atendimento de necessidades sociais variadas de melhoria das condições de vida em geral. Murray, Caulier-Grice e Mulgan (2010) corroboram com essa visão ao afirmarem que a inovação social referese às muitas maneiras em que as pessoas criam novas respostas eficazes para os desafios da humanidade. Estas se caracterizam como novas ideias (sistemas, produtos, serviços e modelos) que atendem as demandas sociais e criam novas relações ou colaborações.

Murray, Caulier-Grice e Mulgan (2010) argumentam ainda que a inovação social pode acontecer em todos os setores da sociedade, público, sem fins lucrativos e privado, mas grande parte das soluções mais criativas tem acontecido nas fronteiras entre esses setores. Com isto, os autores apontam para um novo tipo de economia que combina elementos antigos e novos. Assim, as inovações sociais fazem referência "tanto aos processos sociais de inovação como as inovações de interesse social, assim como também ao empreendedorismo de interesse social como suporte da ação inovadora" (MANZINI, 2008, p.5).

\subsection{Processo de difusão}

Murray, Caulier-Grice e Mulgan (2010) descrevem caminhos para as organizações de inovação social projetarem, desenvolverem e crescerem. Esses métodos variam de formas de pensar à ferramentas práticas para o financiamento ou projeto. Tais autores destacam que as ferramentas de inovação social são desenvolvidas da mistura de ideias criativas e recombinação de diferentes elementos. Exemplos disto são inovações que combinam métodos de financiamento usado para a ciência e capital de risco ou outros que combinam etnografia e técnicas de co-design. No entanto, apesar da riqueza e vitalidade das iniciativas de inovação social, a maioria das pessoas que tenta inovar conhece apenas uma fração dos métodos que existem para acelerar os resultados da organização.

De acordo com Pereira e Campos (2009) o que é unânime nesse cenário é o uso da internet como ferramenta imprescindível para a inovação social. Esta participa desde o surgimento das iniciativas até a consolidação e a difusão para modelos futuros de conformação do tecido social. 
Neste processo é importante observar as possíveis ações que o design pode conceber com a sua capacidade de orientar estrategicamente as próprias atividades. Segundo Manzini (2008, p.28) isto implica em uma considerável "habilidade do design de gerar visões de um sistema sociotécnico sustentável", organizando-as em um sistema coerente de produtos e serviços regenerativos e comunicando-as adequadamente para que sejam reconhecidas e avaliadas "por um público suficientemente amplo, capaz de aplicá-las efetivamente". Assim, o design pode colaborar com as iniciativas de inovação social, considerando algumas das seguintes ações: (i) analisando as tipologias específicas de casos promissores; (ii) destacando suas forças e fraquezas; (iii) intervindo em seus contextos para torná-los mais favoráveis; e (iv) desenvolvendo soluções para aumentar sua acessibilidade, eficácia e replicabilidade (MANZINI, 2008).

Ainda para Manzini (2008, p.98) "os designers sempre criaram pontes entre a sociedade e a tecnologia". No entanto, o foco que quase sempre voltouse à inovação técnica emerge agora para a inovação social. Assim é papel do designer "[...] identificar casos promissores, utilizar sensibilidade, capacidades e habilidades de design para projetar novos artefatos e indicar novas direções para a inovação técnica". Isto para o autor significa conceber e desenvolver soluções habilitantes ou facilitadoras de design.

\section{ESTRATÉGIAS E MÉTODOS}

O escopo desse artigo foi desenvolvido para a proposta de difundir uma iniciativa de inovação social, tendo como estratégia a replicação da ideia e a contribuição do design em soluções facilitadoras para a inovação (Quadro 1). Assim, o método escolhido foi o estudo de caso, que consiste de "uma investigação empírica de um fenômeno contemporâneo dentro do contexto da vida real" (YIN, 2010, p.32), principalmente quando não existe uma separação clara entre o fenômeno e o contexto.

Quadro 1: Estratégias adotadas para o estudo de caso.

\begin{tabular}{|l|l|}
\hline \multicolumn{1}{|c|}{ O quê? } & \multicolumn{1}{c|}{ Como? } \\
\hline \multicolumn{2}{|c|}{ Estratégia I - Replicação da ideia } \\
\hline $\begin{array}{l}\text { Conhecer a iniciativa, desde a sua criação até o } \\
\text { seu processo de implementação, execução e } \\
\text { gerenciamento. }\end{array}$ & $\begin{array}{l}\text { Foi utilizado o DESIS09 Toolkit para a coleta de } \\
\text { dados, além de pesquisa etnográfica e elaboração } \\
\text { de moodboards. }\end{array}$ \\
\hline \multicolumn{2}{|c|}{ Estratégia II - Soluções habilitantes de design para a iniciativa } \\
\hline $\begin{array}{l}\text { Propor melhorias para o modelo de gestão da } \\
\text { iniciativa, analisando seus fatores de sucesso e } \\
\text { risco e suas interações com o sistema. }\end{array}$ & $\begin{array}{l}\text { Foi empregando as seguintes ferramentas: Matriz } \\
\text { FOFA, Mapa do sistema, Mapa de atores, Blueprint } \\
\text { e MEPSS. }\end{array}$ \\
\hline
\end{tabular}

Estratégia I - Replicação da ideia

Conhecer a iniciativa, desde a sua criação até o seu processo de

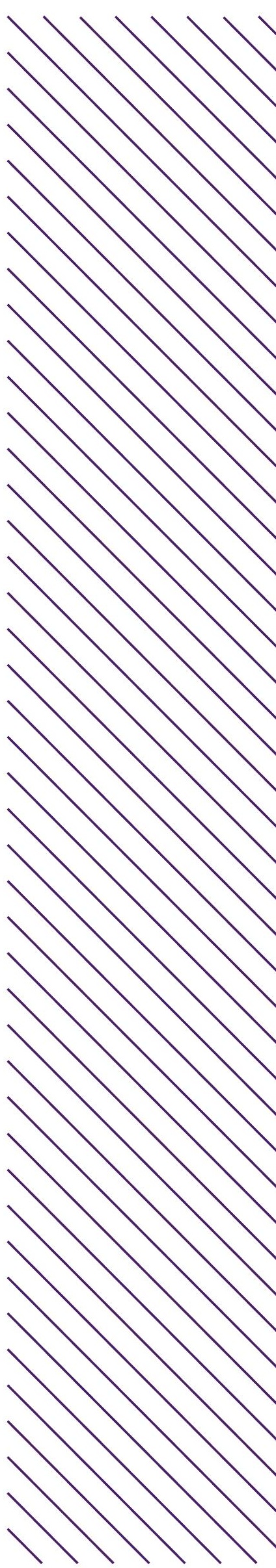


implementação, execução e gerenciamento.

Foi utilizado o DESISO9 Toolkit para a coleta de dados, além de pesquisa etnográfica e elaboração de moodboards.

\section{Estratégia II - Soluções habilitantes de design para a iniciativa}

Propor melhorias para o modelo de gestão da iniciativa, analisando seus fatores de sucesso e risco e suas interações com o sistema.

Foi empregando as seguintes ferramentas: Matriz FOFA, Mapa do sistema, Mapa de atores, Blueprint e MEPSS.

Dentre as ferramentas selecionadas, algumas são indicadas pela rede internacional DESIS, outras são comumente abordadas pelas ciências sociais e pelo design de serviços. O design de serviços é uma abordagem que atua de forma holística, colaborativa e multidisciplinar por integrar sistemas, processos, produtos e serviços com o propósito obter satisfação do usuário, gerar valor, solucionar problemas e promover a sustentabilidade (SACO e GONCCALVES, 2008). A abordagem do design de serviços permite a análise das interações do sistema e do fluxo dos processos.

\subsection{Estratégia I: Replicação da ideia}

Para a avaliação de iniciativas criativas e colaborativas o DESIS09 Toolkit propõe uma série de ações e formatos com a finalidade de coletar, conhecer e relatar casos promissores de inovação social em diversas partes do mundo, visando a sua difusão por replicação da ideia ou engajamento de novos parceiros local ou globalmente. Com esta abordagem, tais ações foram realizadas neste estudo:

a) Pesquisa e discussão de possíveis casos promissores. Para isto, o DESIS09 Toolkit sugere um Light format, ou seja, um formulário guia com orientações para coleta de dados a fim de avaliar a inovação social e selecionar o caso promissor.

b) Realização de pesquisa etnográfica com visita à iniciativa selecionada para coleta de dados aprofundados. Na visita foi realizada entrevista semiestruturada com o responsável pela ideia (organizador) e registro de imagens de situações vividas no caso. O DESISO9 Toolkit apresenta para essa ação dois outros formulários guia, chamados de Interview guide e Photochecklist. Estes deram suporte para a ação por oferecerem um check-list de perguntas e fotos que visam descrever a solução, o contexto, os atores, os artefatos da 
solução, a interação entre as pessoas e o meio ambiente. Nesta fase solicitouse ao organizador a assinatura do Consent Agreement Model para firmar as intenções do estudo de caso e permitir a reprodução de informações e imagens.

c) Elaboração de síntese da entrevista. Foi utilizado nessa ação o formulário In-depth format Analisys do DESISO9 Toolkit. Este visa aprofundar tópicos já indicados no Light format para gerar um documento mais completo sobre o modelo de gestão da iniciativa, seus fatores de sucesso e riscos, sua sustentabilidade econômica, etc.

d) Apresentação visual do caso (Showcase), seguindo o formato In-depth format Visualisation do DESISO9 Toolkit. Por fim, este instrumento orienta o envio do formulário e demais informações à coordenação do DESIS-Brasil para registro e difusão do caso pela própria rede e seus colaboradores.

\subsection{Estratégia II: Soluções habilitantes de design}

O relatório da coleta de dados obtido na estratégia I foi o ponto de partida para o alcance da estratégia II. Nesta ferramentas do design de serviços foram empregadas para promover soluções de design, no que se refere à implementação de maior acessibilidade, eficácia e replicabilidade para a organização. Segundo Manzini (2008) isto pode ocorrer por um processo de design em três etapas:

1) A primeira etapa visa detectar e analisar suas forças e fraquezas. Deste modo, elaborou-se uma matriz FOFA (Forças, Oportunidades, Fraquezas e Ameaças) que combinou visões do próprio organizador da iniciativa, obtidas pela pesquisa etnográfica realizada, com as percepções dos autores deste trabalho.

2) A segunda etapa objetiva conceber e desenvolver soluções (produtos, serviços e comunicação) para aumentar suas forças e diminuir suas fraquezas. Nesta etapa, as ferramenta do design de serviços foram utilizadas com o propósito de criar e adaptar as interfaces da iniciativa, mapeando todos os detalhes dessa jornada. Assim foram criados mapas do sistema e atores da organização, bem como, em um Blueprint, matriz de representação das etapas da iniciativa, foram evidenciadas as interações que ocorrem no sistema da organização e possíveis melhorias para os processos.

3) A terceira etapa propõe o uso de tecnologias novas e especificamente concebidas. Para esta utilizou-se o MEPSS (Metodologia para o sistema de produtos e serviços) com a função de propor a criação de novos modelos, sistemas, processos, produtos ou serviços para a organização. 


\section{ESTUDO DE CASO: OMUNGA GRIFE SOCIAL}

A organização colaborativa e criativa selecionada para o estudo de caso proposto sobre iniciativas de inovação social promissoras no Brasil foi a Omunga Grife Social. Esta se caracteriza como uma organização voltada para a inovação social ao relacionar resultados econômicos da venda de produtos da sua grife com projetos de ação social. Seu propósito é promover melhores condições de vida para crianças e jovens que vivem em regiões de extrema vulnerabilidade social no Brasil e mundo, por meio da educação.

A organização Omunga estabeleceu-se para colaborar com regiões ainda não assistidas, visando diminuir a distância entre os menos favorecidos e os direitos fundamentais de um cidadão. Esses são garantidos pela Declaração Universal dos Direitos Humanos (DUDH) de 1948, a qual descreve em seu art. 26 que: "Todo ser humano tem direito à instrução" (ONU, 1984). A iniciativa endossa que o incremento e a qualidade da educação traz desenvolvimento humano e cidadania, o que impacta em melhores relações sociais e ambientais por amparar a sobrevivência dessas comunidades, potencializar o Índice de Desenvolvimento da Educação Básica (Ideb) na região, reter o conhecimento e formar cidadãos.

\subsection{Modelo de gestão da organização}

O surgimento da Omunga ocorreu pelo anseio do organizador da iniciativa em colaborar com o processo de transformação da sociedade. Assim, com base em suas leituras e pesquisas, o organizador teve conhecimento da solução de inovação social criada em 2000 por John Wood "RoomtoRead1" (2015), sendo esta a sua principal inspiração. Os objetivos da Omunga são: (i) promover o engajamento e empoderamento da comunidade; (ii) construir, equipar e manter bibliotecas; (iii) promover o acesso à leitura especializada e voltada para o desenvolvimento local; (iv) oferecer acesso às tecnologias da informação (TI) e (v) garantir a formação continuada de professores para a melhoria da qualidade da educação. A Figura 1 mostra os projetos, contextos, produtos e resultados já obtidos pela Omunga até o momento. 
Figura 1:Moodboard referente aos projetos sociais

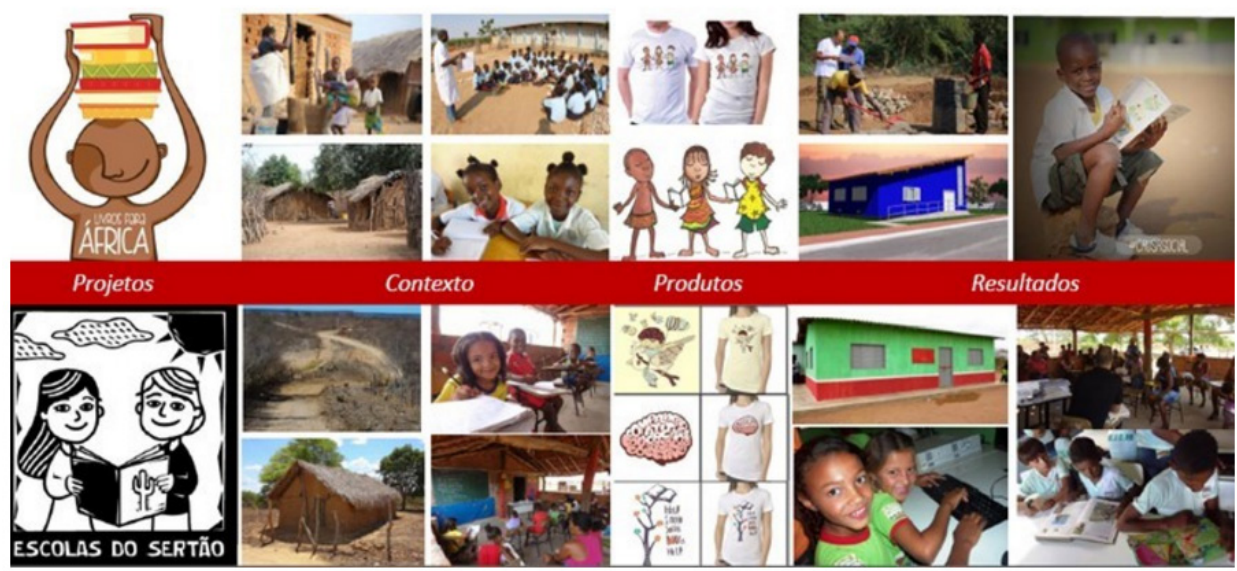

Fonte: Os autores (2015)

Sediada no município de Joinville-SC, a estrutura organizacional da Omunga Grife Social é composta por um organizador, uma estagiária (único colaborador remunerado), uma bibliotecária, 15 profissionais voluntários de diferentes qualificações, 35 empresas voluntárias parceiras, entre outros. A interação com a sociedade ocorre pelo uso intensivo de redes distribuídas de comunicação ou pontos de contato na linguagem do design de serviços. A iniciativa possui site oficial, loja virtual, blog, fotos e vídeos divulgados na internet. Esta oferece também contato e atendimento por e-mail, celular e endereço fixo do escritório administrativo. Contudo, o principal ponto de contato da iniciativa para o engajamento de colaboradores desenvolveu-se na forma de grife, ou seja, produtos exclusivos de uma marca. A cada projeto social, a organização lança uma série de camisetas com estampas personalizadas por designers e artistas que são convidados a criarem ilustrações sobre os temas da ação. O objetivo dos produtos, além da difusão da ideia, é a comercialização para custeio dos projetos.

O método de ação social da instituição baseia-se na elaboração de projetos sociais amparados por uma estrutura de negócio. Os componentes técnicos necessários para que os projetos sociais ocorram são: (i) formação de uma equipe executora de profissionais voluntários; (ii) indicadores de referência social; (iii) acesso à comunidade determinada; (iv) articulação dos líderes locais, poder público, iniciativa privada e terceiro setor; ( $v$ ) design gráfico do projeto para a divulgação e comercialização; e (vi) mobilização e engajamento da sociedade para colaborar com o projeto.

O método de ação por projetos da Omunga Grife Social ocorre inicialmente pela pesquisa de regiões não-assistidas. Isto é realizado com o auxílio de dados coletados por meio de relatórios de indicadores sociais. Após identificado as regiões, a situação das comunidades é averiguada com a coleta de informações

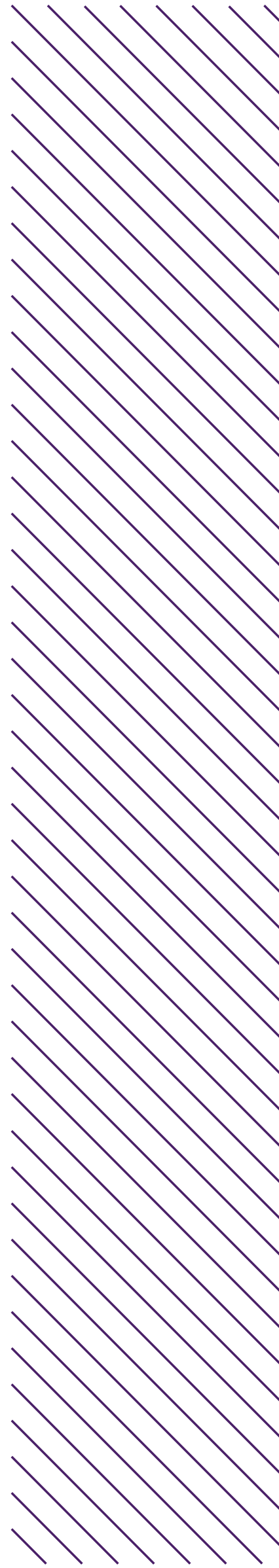




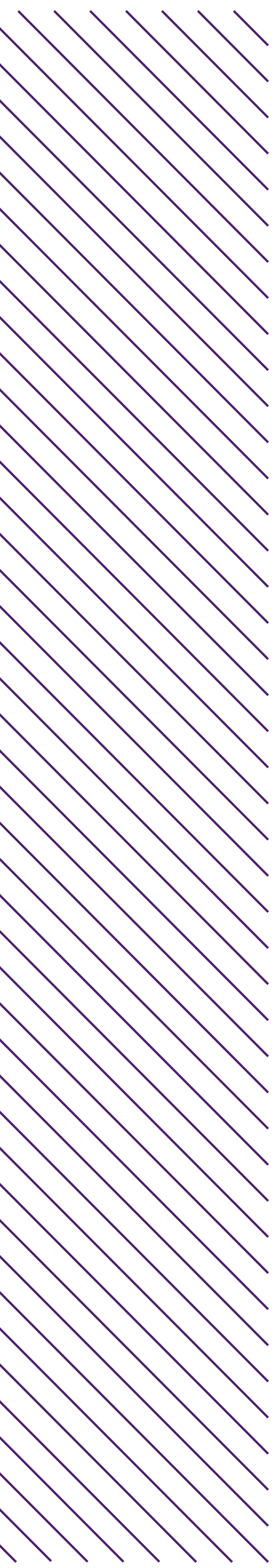

via internet e por visitas in loco. São analisados a cultura, o modo de vida e as necessidades sociais da comunidade. Nas visitas líderes comunitários e a gestão pública local são articulados quanto aos propósitos da iniciativa. Assim, na próxima etapa, a ação ganha formato de projeto, com nome próprio, marca, produtos personalizados e campanhas de divulgação e comercialização. Isto ocorre com o objetivo de mobilizar intensivamente a sociedade em seus diferentes papéis (clientes, voluntários, fornecedores e parceiros).

A contrapartida da organização nos projetos é justamente essa ação por projeto, além do montante arrecadado com a venda dos produtos. Deduzido gastos administrativos, estes são transformados em livros, computadores e mobiliário para a instalação de bibliotecas. A contrapartida das demais partes interessadas é o apoio financeiro e humano para a construção e manutenção do espaço destinado à biblioteca, bem como para a realização das oficinas de capacitação continuada oferecida aos educadores da região. Com as bibliotecas concluídas e inauguradas a organização presta contas junto à sociedade e aos parceiros, destacando a contribuição de todos os envolvidos no processo. Com isso, nova fase do projeto tem início, a de promover a qualidade no ensino por meio das oficinas de capacitação. Por dois anos os voluntários da Omunga deslocam-se até a região para apoiar a realização das oficinas. A continuidade dessa ação, após os 24 meses de acompanhamento, deve ser realizada pelo poder público e a comunidade local.

\subsection{Forças, oportunidades, fraquezas e ameaças da iniciativa}

Durante a análise do caso, ferramentas foram utilizadas para guiar o processo de compreensão e melhoria da organização. A análise FOFA (Figura 2) foi empregada para a formulação de novas estratégias ou soluções. Esta se apresenta por uma matriz dividida em dois cenários de estudo, o atual e o futuro, e tem a finalidade de detectar fatores críticos e de sucesso da organização. Assim, o modelo combina forças e fraquezas referente àqueles fatores que podem ser controlados pela organização (ambiente interno), com oportunidades e ameaças do ambiente externo que podem ser apenas monitorados. 


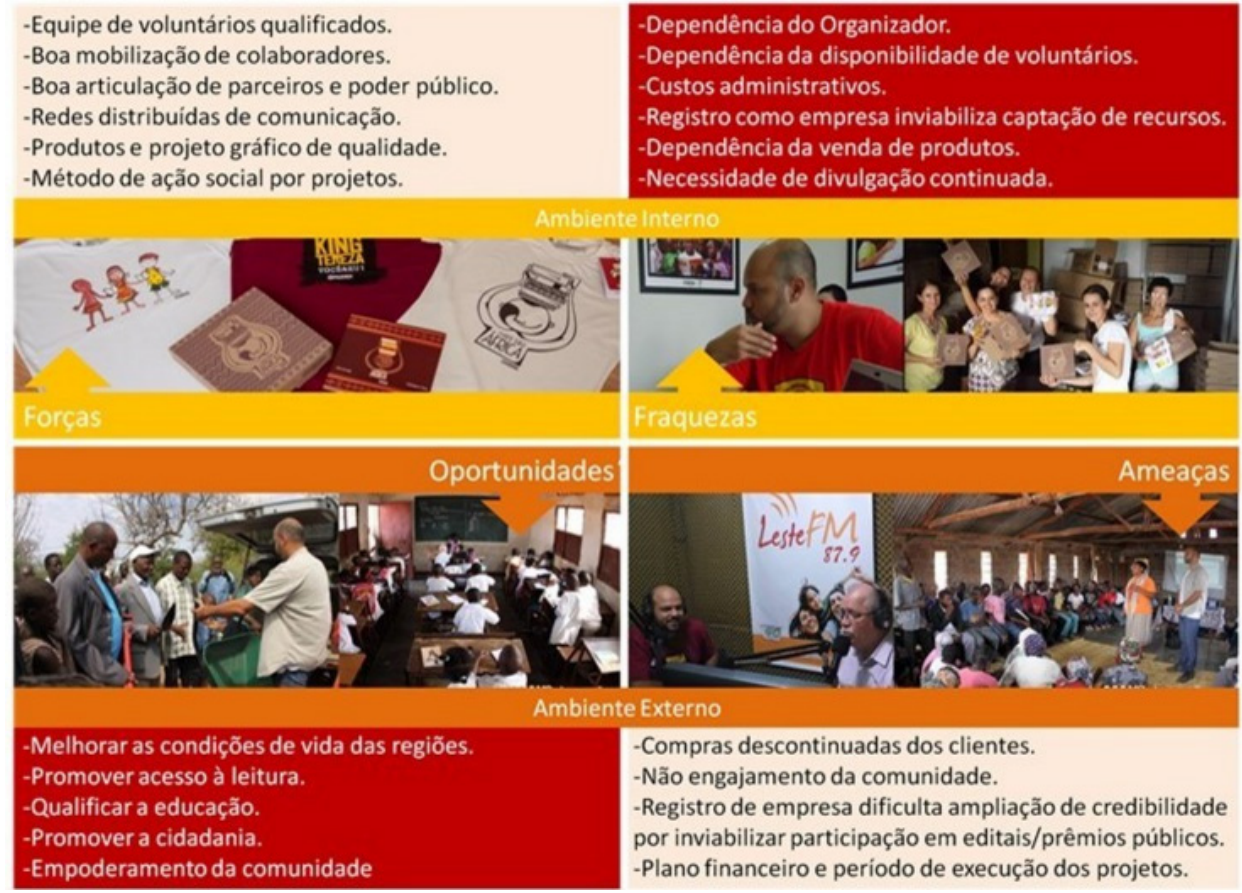

Fonte: Os autores (2015)

Assim, alguns dos fatores de sucesso destacados na matriz FOFA foram: a qualidade dos produtos; a capacidade de articulação e mobilização do organizador; a agilidade em obter resultados; a solução estar fortemente sustentada em indicadores sociais; o incentivo à formação continuada dos educadores; o direcionamento para o desenvolvimento local; a busca pela expansão do indivíduo como cidadão e o empoderamento da comunidade.

No entanto, como fatores de risco tem-se inicialmente um possível conflito entre os líderes da comunidade e da organização, devido à interferência cultural e a própria desconfiança quanto aos propósitos da iniciativa. Há também a questão de gênero ou empoderamento da mulher. Acredita-se também que com a consolidação das causas já iniciadas, bem como com a possibilidade da instituição ser credenciada para participar de premiações e concursos nacionais e internacionais trará credibilidade e reconhecimento à grife social. Um outro ponto crítico sobre a mudança sustentável pode estar na organização caracterizar-se como uma Grife, ou seja, obter recursos parciais por meio do incentivo ao consumo. Entretanto, como fator de alto risco evidenciou-se a iniciativa centralizar-se no poder de comunicação do organizador, o que indica baixa capacidade da iniciativa sustentar-se na ausência deste. 


\subsection{Mapa do sistema e atores da organização}

Com a combinação dos cenários de fatores de risco e sucesso, um Mapa do Sistema ou Mapa Sistêmico foi realizado. Este tem a função de simular, por forma gráfica, os padrões de comportamento da instituição ou comunidade por meio da identificação das relações causais entre os fatores e a situação de interesse em análise (VEZZOLI, 2010). O Mapa do Sistema (Figura 3) do caso estudado possibilitou gerar informações úteis para a visualização do contexto da forma de atuação da organização quanto à relação dos seus produtos, serviços e participantes, já que esta enfatiza a sua atuação por um sistema integrado de produtos e serviços (Product-Service System - PSS)2.

Figura 3: Mapa de Sistemas

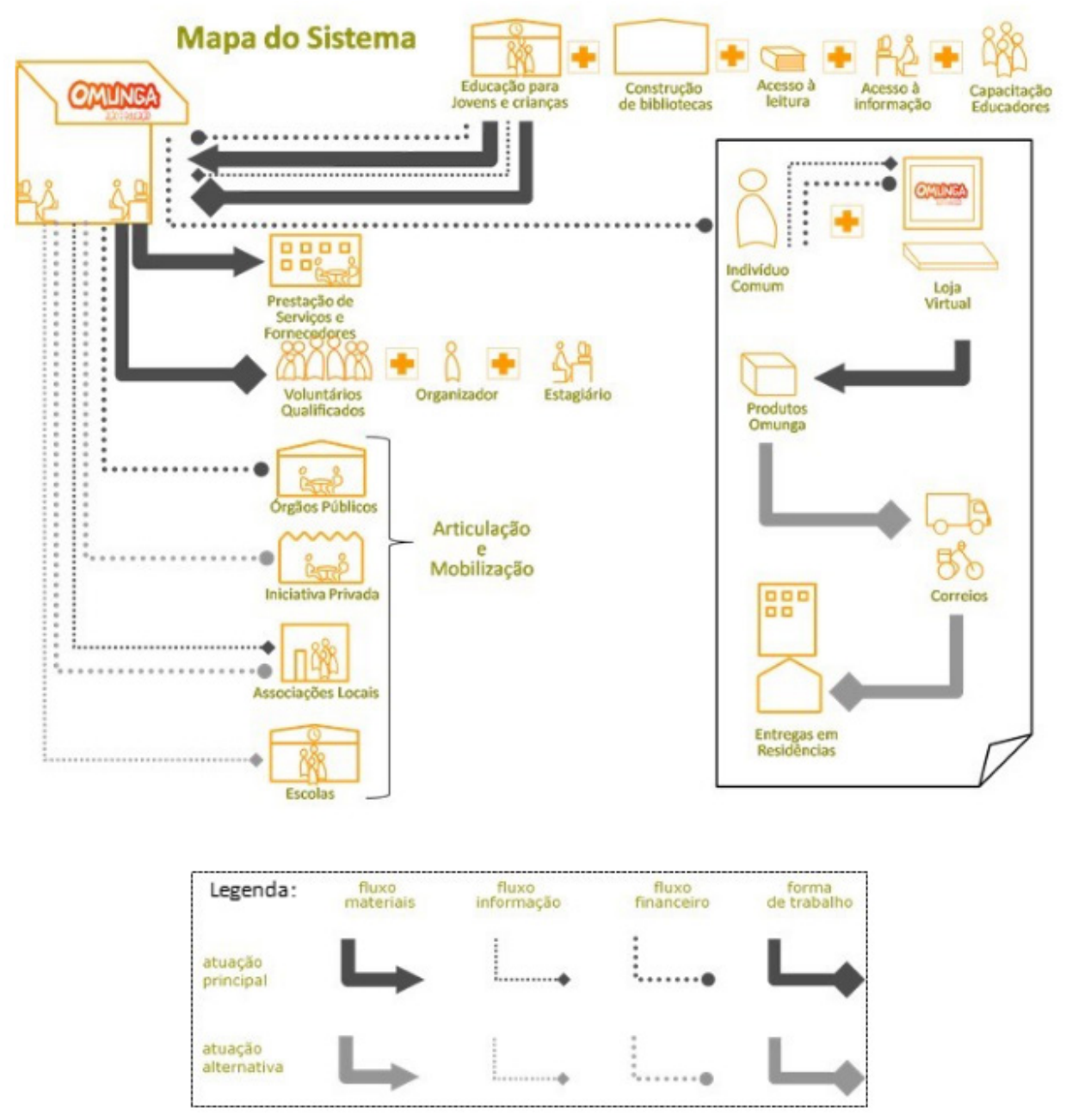

Caixa de Textolmagem

Fonte: Os autores (2015)

O PSS da instituição enquadra-se na definição de sistema orientado ao serviço. Neste tipo de PSS, Neely (2008 apud Clayton, Backhouse e Dani, 2012) diz que a propriedade do produto físico ou tangível é transferida ao cliente e 
serviços de valor agregado são oferecidos como parte integrante da oferta. Deste modo, a Omunga Grife Social vende produtos personalizados com a oferta de utilizar o capital arrecadado para o fomento de serviços de interesse social como geração de valor.

Na sequência, um Mapa de Atores (Figura 4) da iniciativa foi elaborado com o propósito de identificar os papéis de todos os envolvidos no PSS. Pelo desenvolvimento do Mapa de Atores foram identificados como participantes ativos da iniciativa: o organizador, os compradores/clientes e os voluntários/ executores, além do poder público e da iniciativa privada que atuam como parceiros. Como atores passivos ou usuários tem-se crianças e jovens em situação de extrema vulnerabilidade social. Estes também são compreendidos como os beneficiados pela ação social, juntamente com os seus familiares, os educadores, o poder público local, a comunidade e a sociedade como um todo.

Figura 4: Mapa de Atores

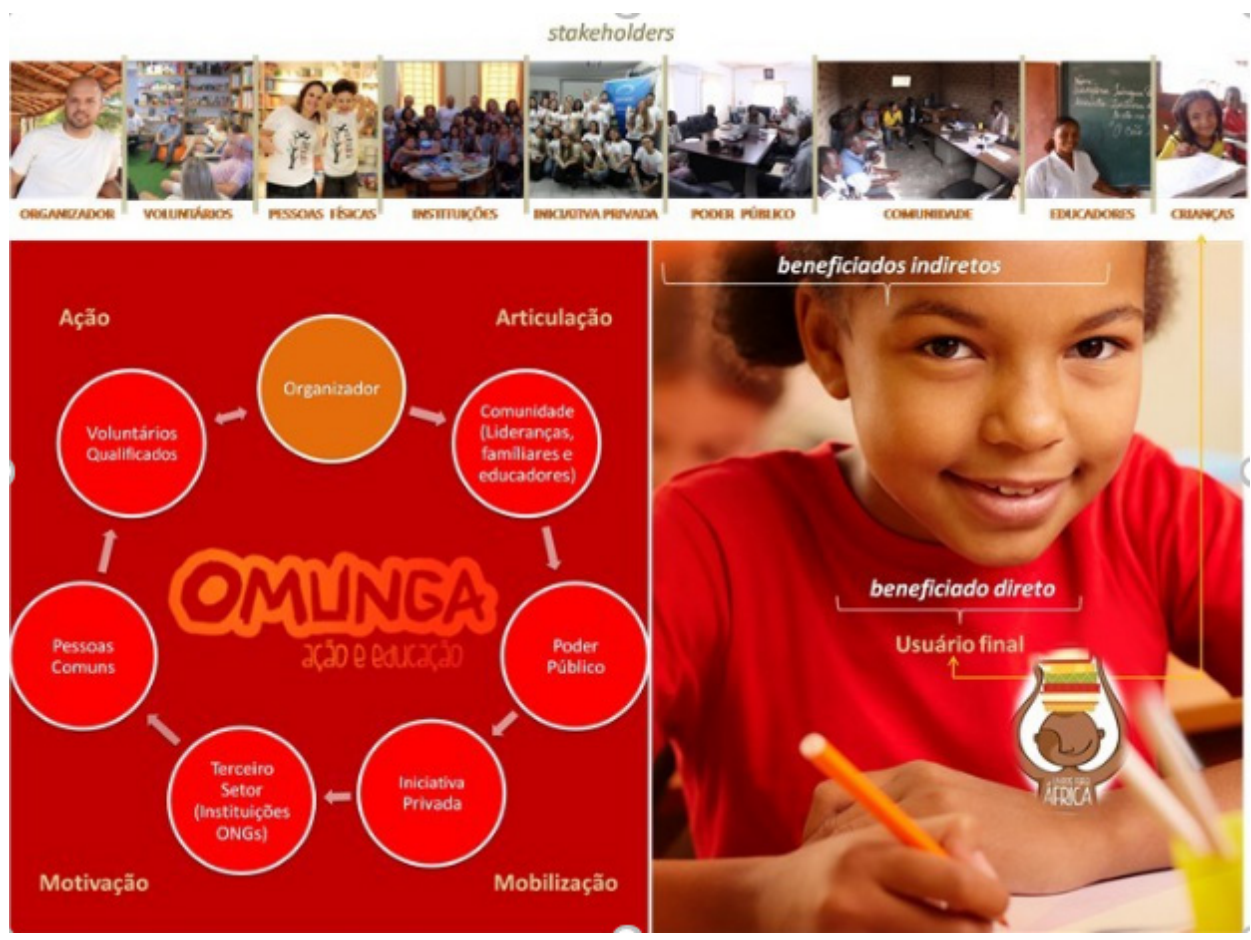

Fonte: Os autores (2015)

Para o organizador, demais profissionais voluntários e os clientes/ compradores a motivação para atuarem nas ações sociais é a busca de benefícios pessoais, como construção de uma vida com significado por engajamento e transformação social, bem como, muitas vezes, por enaltecimento do ego ou modismo. Para o poder público os benefícios são de agilidade nas ações, já que a execução de projetos que partem do governo são onerosos e burocráticos. Quanto à iniciativa privada isto se reflete em responsabilidade social para empresa, o que é benéfico para a sua imagem. Quanto aos usuários finais (as

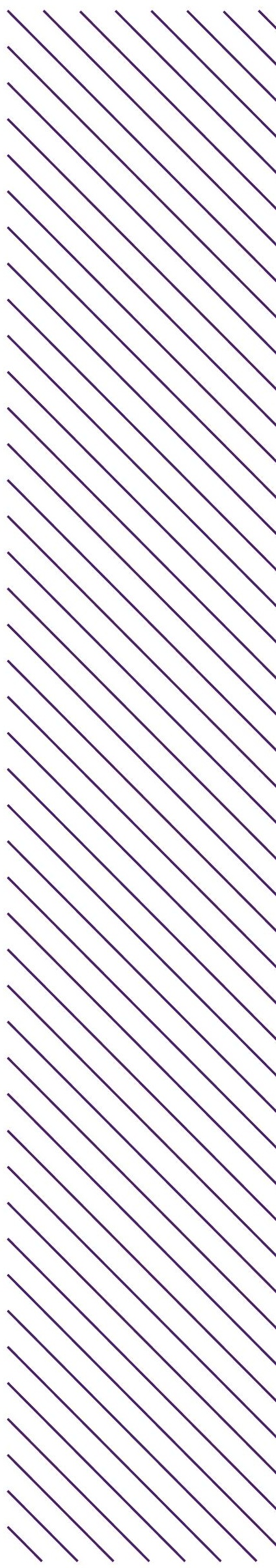


crianças e os jovens), seus familiares, os educadores e a comunidade local, os benefícios são de sobrevivência e busca de novas perspectivas de vida. As causas da iniciativa são benéficas também ao meio ambiente, pois promovem o direito à cidadania como elemento constituinte para a sustentabilidade. A formação de um cidadão acarreta no reconhecimento de direitos, na promoção da autonomia e na valorização da diversidade e da biodiversidade.

\subsection{Uso do Blueprint e MEPSS}

Aplicou-se a ferramenta Blueprint (Figura 5) para entendimento claro dos componentes, das etapas e das interações do PSS. Vianna et al. (2012) definem essa ferramenta como uma matriz onde são mapeados os diferentes pontos de contato de um PSS, as ações do cliente e de toda a interação com a empresa desde as operações visíveis até aquelas que ocorrem na retaguarda.

Figura 5: Blueprint

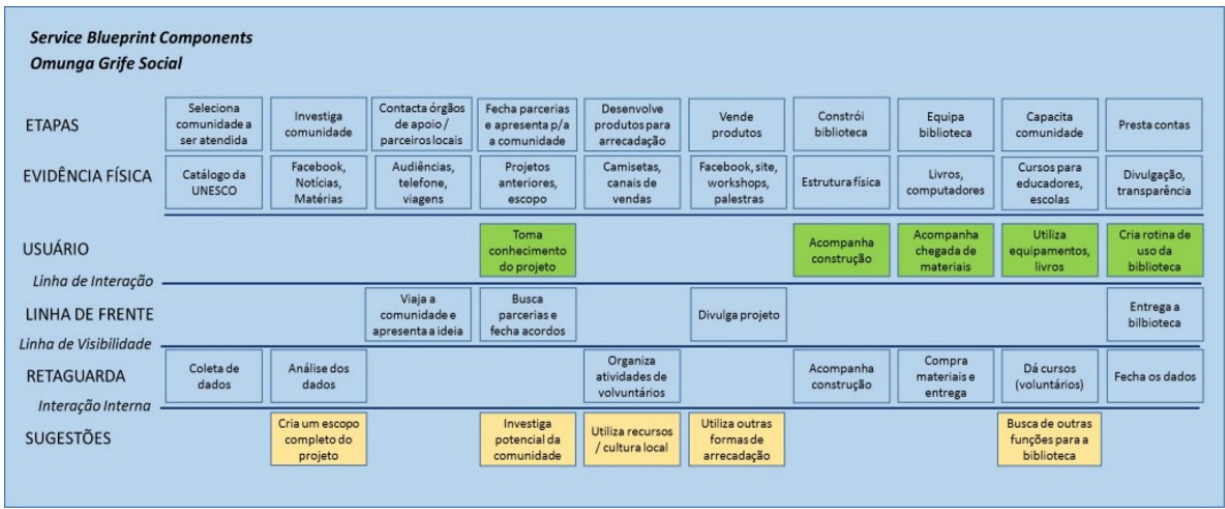

Fonte: Os autores (2015)

Identificou-se o envolvimento de grupos de pessoas em vários momentos das etapas do PSS da iniciativa. Isto mostrou que os atores do sistema não são fixos e mudam de função de acordo com o andamento dos projetos. Assim, o Blueprint, por atuar baseado nas etapas do serviço, permitiu visualizar lacunas e sobreposições do sistema e sugerir possíveis melhorias na própria matriz da ferramenta.

Na aplicação específica do caso Omunga Grife Social, o blueprint ratificou os resultados obtidos pelo MEPSS. Houve uma coincidência significativa nas sugestões oriundas do MEPSS e do Blueprint, demonstrando que ambas ferramentas são adequadas às etapas de busca de melhoria com a concepção de novas tecnologias para a iniciativa.

O MEPSS (2015) trata-se de uma análise em dimensões associadas à 
sustentabilidade ambiental, social, ética e econômica do PSS foco de estudo. Nesta ferramenta optou-se por utilizar os campos que auxiliam na busca de soluções, promovendo um brainstorming de ideias, guiado por perguntas. O resumo gráfico da estrutura do MEPSS da organização está apresentado na Figura 6. Assim, obteve-se uma série de possíveis soluções que foram selecionadas para compor a proposta de melhoria do sistema.

Figura 6: Resumo gráfico do MEPSS

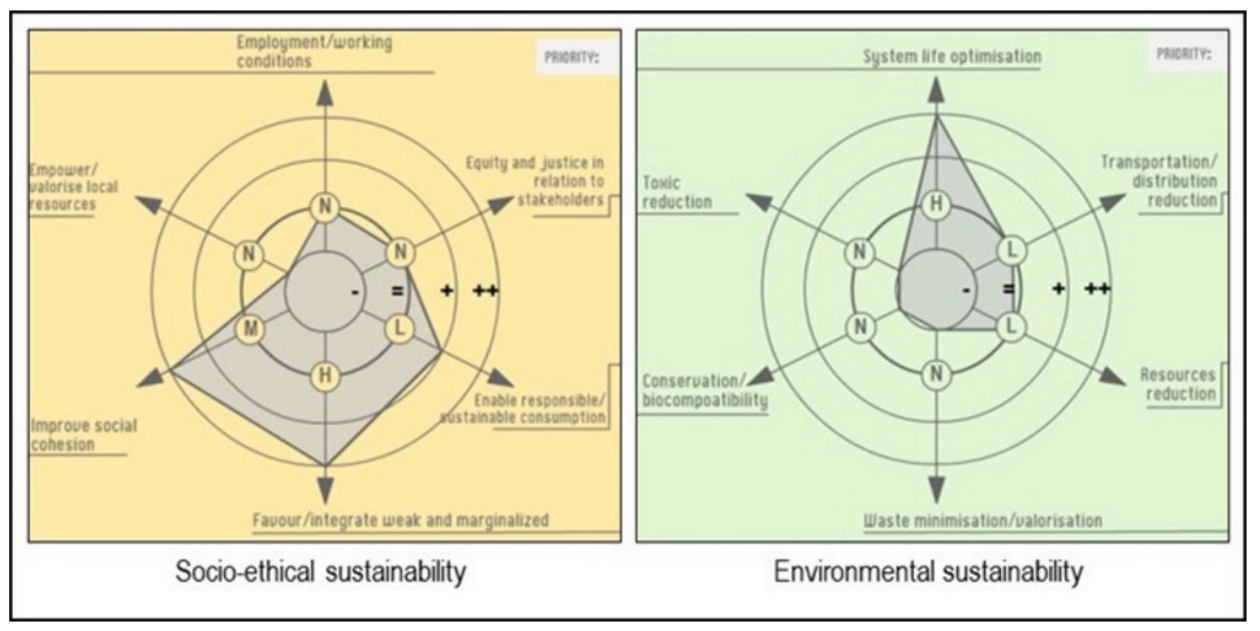

Fonte: Os autores (2015)

Como resultado da aplicação desta ferramenta entendeu-se a necessidade de uma melhoria no modelo de gestão e dos projeto de ação social da organização, com a criação de um modelo de formato ou escopo-padrão. Isso oportunizaria maior eficácia, acessibilidade e replicabilidade para a inovação social da iniciativa. Este modelo deve conter um planejamento estratégico com os possíveis riscos do projeto, as métricas de avaliação da ação bem como os indicadores para análise dos resultados de cada projeto.

\section{CONCLUSÃO}

Este trabalho alcançou o seu objetivo ao promover a difusão da iniciativa da Omunga Grife Social por meio do estudo de caso com aplicação das estratégias de replicação da ideia e de soluções de design. Estas estratégias unidas formaram um conjunto de ações e agiram como delineadores da organização em questão, entendendo suas especificidades e contribuindo com melhorias para seu processo quanto à aceleração das suas potencialidades de acessibilidade, eficácia e replicabilidade.

O desenvolvimento deste trabalho permitiu identificar oportunidades de melhoria na atuação da organização avaliada e, também, propiciou a

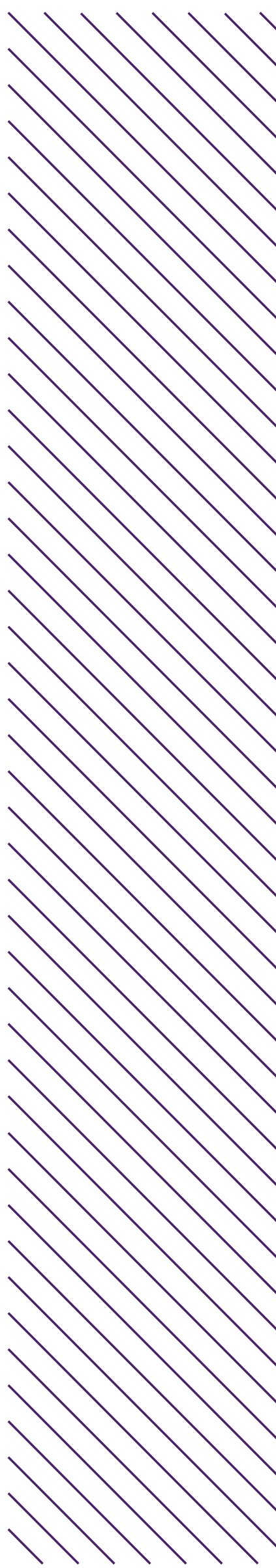


compreensão e o uso de diversos métodos e ferramentas de apoio, que quando combinadas alcançam resultados mais expressivos.

O DESIS09 Toolkit foi um guia importante para a realização das atividades do estudo. A sua estrutura e sequência orientou o conhecimento e análise do modelo de gestão da iniciativa. Como resultado desta análise obteve-se a compreensão ampla da estrutura da organização colaborativa e criativa e suas correlações com os envolvidos, sendo inclusive um instrumento de auto-análise para a próprio organização. Assim, a importância da estratégia de replicação, pautada pelo passo-a-passo do toolkit da Rede DESIS, está na análise do contexto da inovação social que a iniciativa promove. Esta compreensão contextual nem sempre é explícita devido aos projetos sociais possuírem base simplesmente no idealismo de pessoas. Assim, a estratégia I resultou no entendimento e na avaliação de modo amplo da organização para os pesquisadores desse trabalho, o que foi muito importante para a aplicação da estratégia II.

A aplicação da estratégia II permitiu identificar que a situação que não possui uma linha clara de atuação da Omunga estava na estrutura dos seus projetos sociais. Não foi percebido um escopo de projeto claro com metas, etapas e indicadores. Foi evidenciado ainda no estudo de caso, que atrasos na execução dos projetos modificava o seu orçamento, necessitando assim de maior arrecadação de recursos. Essa é uma variável difícil de ser controlada ao considerar que os projetos dependem de vendas de produtos, que impactam diretamente nos prazos de execução das bibliotecas. Outra questão que também mereceu atenção foi os indicadores de sucesso, já que não há um claro controle dos momentos posteriores às entregas das bibliotecas às comunidades. Em relação aos índices de educação local existe a dificuldade de acompanhamento e identificação da influência da biblioteca na região. A arrecadação de fundos poderia ter o aporte de outras doações ou patrocínios, inclusive a de se considerar o crowdfunding, bem como potencializar a participação da iniciativa em premiações sobre inovação como as da Financiadora de Estudos e Projetos (FINEP). Outras questões como o aproveitamento dos recursos e mão-deobra locais para a criação de produtos seriam pontos de análise de viabilidade. Porém, entende-se que todas as análises para cada projeto deveriam partir de um escopo-padrão que serviria, entre outras coisas, de um roteiro, check-list e acompanhamento das etapas, prazos, custos, indicadores de qualidade e recursos humanos necessários para o desenvolvimento de cada projeto.

Por fim, o estudo de caso mostra que organizações voltadas à inovação social ainda carecem de modelos de gestão próprios e adequados às suas ênfases de preencher lacunas que o Estado e as iniciativas privadas não conseguem resolver, propiciando a regeneração do tecido social. Por outro lado, o design pode ser um grande contribuinte para a melhoria das iniciativas de inovação social, pois este é capacitado para desenvolver soluções em várias esferas, 
dentre as quais enquadram-se a replicabilidade e as soluções facilitadoras. Sendo assim, a compreensão da análise e resultados de estudos de design como elemento estratégico em organizações com fins sociais contribui para demonstrar que esta interação, desde que estruturada, pode trazer resultados significantes nos projetos de iniciativas de inovação social.

\section{REFERÊNCIAS}

CLAYTON, R. J.; BACKHOUSE, C. J.; DANI S. Evaluating existing approaches to product-service system design: A comparison with industrial practice. Journal of Manufacturing Technology Management, v.23, n.3, p.272-298, 2012.

DESIS-NETWORK. Design for Social Innovation and Sustainability. Disponível em: <http://desis-network.org/>. Acesso em 01/07/2015.

EU COMMISSION. Innovative Business Models with Environmental Benefits. Final report, n.4, nov., 2008.

MANZINI, E. Design para a inovação social e sustentabilidade. Cadernos do Grupo de Altos Estudos, Programa de Engenharia de Produção da Coppe/UFRJ, Rio de Janeiro, v.1, 2008.

MANZINI, E.; PENIN L.; GONG, M.; CIPOLL, C.; M'RITHAA, M.; MENDOZA, A. The DESIS Network: Design and Social Innovation for Sustainability. In: The Journal of Design Strategies: Change Design. v. 4, n.1. p. 14-21, Spring, 2010.

MANZINI, E.; VEZZOLI, C. A strategic design approach to develop sustainable product service systems: examples taken from the "environmentally friendly innovation" Italian prize. Journal of Cleaner Production, 11, 8, p. 851-857. 2003.

MEPSS. Methodology for PSS. Disponível em: www.mepss-sdo.polimi.it. Acesso em 01/07/2015.

MURRAY, R.; CAULIER-GRICE, J.; MULGAN, G. The Open Book of Social Innovation. London, NESTA/The Young Foundation, 2010. Disponível em: <http://www.nesta.org.uk/publications/assets/features/the_open_ book_of_social_innovation>. Acesso em: 01/07/2015.

ONU. Declaração Universal dos Direitos Humanos. 1984. Disponível em: <http://nacoesunidas.org/declaracao-universal-dos-direitos- 
humanos/>. Acesso em 01/07/2015.

PEREIRA, C.; CAMPOS, J. L. Design para a sustentabilidade: o tecido social em processo de re-singularização. bocc. p.1-6, 2009. Disponível em <http://www.bocc.ubi.pt/pag/pereira-design-bocc-05-09.pdf>. Acesso em: 01/07/2015.

ROOM TO READ. Disponível em <http://www.roomtoread.org/>. Acesso 01/07/2015.

SACO, Roberto M.; GONÇALVES, Alexis P. Service Design: An

Appraisal. Design Management Review. v.19, n.1, p. 10-19, 31 mar, 2008.

VEZZOLI, C. Design de sistemas para a sustentabilidade: teoria, métodos e ferramentas para o design sustentável de "sistemas de satisfação". Carlo Vezzoli - Salvador: EDUFBA, 2010.

YIN, R. K. Estudo de caso: planejamento e métodos. 4. ed. Porto Alegre: Bookman, 2010. 


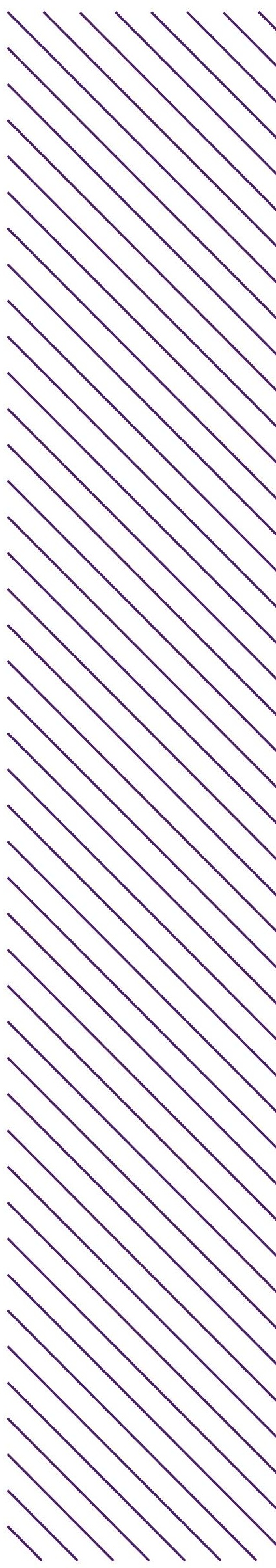

